\title{
An Empirical Analysis of the Determinants of International Digital Divide
}

\author{
Liu Yun ${ }^{1}$ \\ Business Department, Xiamen university of technology, \\ No 600,ligong Rd,Jimei District,Xiamen,P.R.China,FL:361024 \\ Tel:13906036625;Email:liu.racky@gmail.com
}

\begin{abstract}
International Digital Divide is an imbalance state of ICT penetration between countries. This paper analyzes the current status and trends of international digital divide, adopts Gompertz technology diffusion model to verify the determinants of ICT penetration level and diffusion rate separately. Finally, China should use "policy levers" to strengthen international trade cooperation, improve the capability of independent innovation, and achieve Chinese goal of bridging digital divide.
\end{abstract}

\section{Introduction}

Digital divide is a new phenomenon emerging with the development of Information and communication technology (ICT). ICT creates a new group of leading technology, changing the technical foundation of the economic development, and eventually leads to a fundamental change in social economic production.

Rapid growth of ICT adoption in developed countries is raised the specter of international digital divide and marginalized developing countries. From a narrow view, the digital divide between different entities represents universal unbalanced state on the Internet and the proliferation of new ICT products. This paper analyzes the main ICT penetration and diffusion rate between countries, gives an objective description of the status quo and development trends of international digital divide. A Gompertz technology diffusion model is used to study the determinants of ICT penetration and diffusion empirically, focusing on Chinese proposals for bridging digital divide.

Please use the following format when citing this chapter:

Yun, 1.., 2007, in IIIIP Intenational lederation for Information Processing, Volume 252, Integration and Innovation Orient to L-Sociely Volume 2, eds. Wang, W., (Boston: Springer), pp. 445-452. 


\section{Status and Trends of the International Digital Divide}

According to the data available, I choose a sample of 43 countries and regions to analyze the current situation and development trends of international digital divide.

Firstly, the global ICT penetration levels were rising during 1998-2004. The initial speed was relatively slow, but in 2000 proliferation was notably faster, with telephone and the Internet was most evident in the trend of changes in the basic Stype show, lots of literatures have proven rapid development of Internet in 2000 was the critical mass.

Secondly, in order to objectively observe changes in the level of ICT penetration, logarithmic ratio of four ICT products penetration level in 2000 and 2004 is used to show the ICT proliferation of diffusion rate. As shown in Fig 1, the diffusion rate of Internet users is faster than the telephone and personal computers. The proliferation of Internet hosts speed greater volatility and some countries of them have even negative growth. This shows that since 2000, the popularity of Internet users significantly raise. However, the Internet hosts might be influenced by more complex factors, show irregular variations.

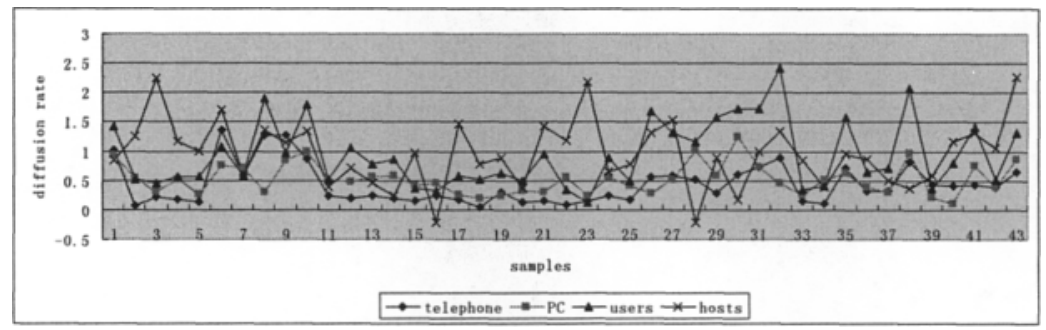

Fig.1. ICT diffusion rate in countries, 2000-2004

Finally, I choose average value, standard deviation and dispersion coefficient of global ICT penetration to describe the trend of changes in the international digital divide. The level of telephone penetration has increased and the standard deviation remains basically unchanged after 2000. Dispersion coefficient was decreased significantly from 2000. Judging from the trend of development, especially in 2000, global ICT penetration was in the narrow dispersion, and international digital divide was in narrowing trend. On this basis, I try to choose different econometric model, both in absolute and relative speed, to observe determinants of the ICT penetration level, to identify the root causes of the digital divide, to explain the factors that affect all countries. In order to make developing countries realize technical leapfrogging, the fundamental way should be used to catch up with developed countries. 


\section{Variable Selection}

\subsection{Dependent Variables}

As mentioned above, this paper selects four ICT indicators as dependent variables, including telephones per 1,000 inhabitants, personal computers per 1,000 inhabitants, Internet hosts per 10,000 inhabitants and Internet users per 1,000 inhabitants. The data on the variables are for the period 2000-2004 and taken from the website of the International Telecommunication Union.

\subsection{Independent Variables}

(1) Income per capita. This paper assumes that there is a positive correlation between the level of income per capita and level of ICT diffusion rate. Countries with higher income per capita levels will invest more money in research and development, more access to use advanced ICT. In this paper, I adopt GDP per capita (PPP international dollars) as the proxy for variables.

(2) The Level of Urbanization. I hypothesize that the development of the Internet economy might allow a higher density of ICT community. On the other hand, the proportion of urban population in a certain city reflects a country's level of industrialization and the development of the service industry [1-2]. The greater proportion of the urban population, the higher the level of industrialization, and lower the level of agriculture.

(3) Education Level. Early researchers [3-4] believe that there is a significant positive correlation between the level of education and penetration of ICT, low level of education and literacy rates mean a lower level of a country's human capital, it's the main factors hindering the popularization of ICT. Higher level of education can promote ICT penetration, and gradually reduce the learning costs, increase the economic value of technology (Hargittai, 1999) [5]. Therefore, I assume that the level of education is an important factor and chose a country's higher education enrollment rate to represent it.

(4) Information Infrastructure. Information infrastructure is a prerequisite for the adoption of ICT. In this paper represent variables is the number of telephone lines per 1,000 inhabitants.

(5) Regulatory Standards. I assume the government's competition policy and regulatory system impact the ICT diffusion. It will also affect a country's supply and use density of ICT. This paper adopts the Government Regulatory Quality Index (promulgated by the World Bank Institute) as a variable, on behalf of a national government's work efficiency and the quality of economic operation of the regulatory system.

(6) Market Openness. "Imperfect information leads to reduction of trade" (Stiglitz, 1989) [6]. On the one hand, ICT can reduce the space of distance of global trade, thereby reduce information asymmetry. On the other hand, in the process of trade and technology transfer, knowledge and technology spills over. Therefore, I 
assume that there is a positive correlation between a country's market openness and ICT diffusion rate, and choose trade proportion of GDP as a proxy variable.

(7) Technology Innovation. ICT products is not only consumer goods, but also a kind of investment products, therefore, I here join the indicator to reflect a country's level of scientific research. The proportion of total industrial exports of high-tech products used here as a representative of variables.

\section{Empirical Models}

In light of the current development of international digital divide, first of all, this paper at first adopts multiple linear regression equation for the static analysis of ICT penetration, which comes to the conclusion that the study results are consistent with previous studies, The level of education and Per capita income are most important factors affecting the level of ICT penetration. Therefore, this paper focuses on analysis of ICT diffusion from the dynamic approach.

A Gompertz technology diffusion model (Chow, 1983) [7] is adopted to study the determinants of ICT diffusion speed. The model assumes that the ICT diffusion rate $(\mathrm{n})$ is proportional to the log difference between the current level and long-run equilibrium level (the latter is determined by a series of exogenous variables ${ }^{X_{j}}$ ).

$$
n_{t}=\theta\left(\log n_{t}^{*}-\log n_{t}\right)
$$

$n_{t}$ means the speed of ICT diffusion during $t$ period. To facilitate estimation, I use the following equation to approximate expressions (1):

$$
\log n_{t}-\log n_{t-1}=\theta\left(\log n_{t}^{*}-\log n_{t-1}\right)
$$

Which

$$
\log n_{t}^{*}=\beta_{0}+\sum_{j=1}^{n} \beta_{j} \log X_{j t}
$$

$x_{n:}$ : the proliferation of explanatory variables affecting ICT

Through alternative and increased random errors, we have estimated the following equation:

$$
\log n_{t}-\log n_{t-1}=\theta \beta_{0}+\sum_{j=1}^{n} \theta \beta_{j} \log X_{j t}-\theta \log n_{t-1}+\varepsilon_{t}
$$

In this paper, the cross section data of 43 national sample during 2000-2004 is used, aiming at telephones, PCs and Internet users and hosts. Based on different variables, the three models were used to estimate as following:

Model- I :

$$
\log N_{04}^{T}-\log N_{00}^{T}=\theta \beta_{0}-\theta \log N_{00}^{T}+\sum_{j=1}^{n} \theta \beta_{j} \log X_{j 04}+\varepsilon_{04}
$$


$N_{04}^{T}$ And $N_{00}^{T}$ represent four different ICT indicators expressed in the 2004 and 2000 , which $T \in$ (phone, $P C$, Internet users, Internet hosts) $(j \geq 1 \ldots n)$, j is the value of the explanatory variable in 2004.

Model- II :

$$
\log N_{04}^{T}-\log N_{00}^{T}=\theta \beta_{0}-\theta \log N_{00}^{T}+\sum_{j=1}^{n} \theta \beta_{j} \log X_{j 04}+\theta \gamma D D+\varepsilon_{04}
$$

DD is a dummy variable reflects the overall state situation, 1 for the developed countries, 0 for developing countries.

Model-III:

$$
\log N_{04}^{T}-\log N_{00}^{T}=\theta \beta_{0}-\theta \log N_{00}^{T}+\sum_{j=1}^{n} \theta \beta, \log X_{j 04}+\sum_{k=1}^{m} \theta \gamma_{k} D_{k}+\varepsilon_{04}
$$

$D_{k}(\mathrm{k}=1 \ldots \mathrm{m})$ is a dummy variable reflects regions of the virtual vector $(\mathrm{D} 1=1$ : samples of specific Asian countries. D2 = 1: Eastern European transition countries, D3 = 1: Latin American and African countries).

\section{Empirical Results}

This paper use 43 countries cross-section data during 2000-2004, analyzes four ICT indicators. According to research result of Ben and Pohjola (2002) [7], technology diffusion changed with time. Model parameter $\theta$ depends on the time interval. As I select time interval 2000-2004, In view of the proliferation of the Internet in 2000 after the peak time of the web, the shorter time spans, the shorter time interval has little impact on diffusion speed. On the other hand, in the late 1990s, ICT diffusion speed went faster in the past five years, compared with the 20 th century, the mid1990s; the ICT diffusion rate may have significantly changed. ICT is in a period of rapid expansion. Although only a sample of 43 countries, the regression statistics are quite robust. Table 1 shows the empirical results associated with telephone diffusion, reflecting national and regional characteristics and features by adding the dummy variables. Different from the results of previous studies, the income per capita levels are negatively correlated with the telephone diffusion speed. I think that to some extent, the results in the initial spread of ICT products shows income per capita levels may be an important factor affecting the diffusion rate, but since 2000 , with telephones and services continue to grow, ICT prices drop rapidly. The consumption level of products and services will no longer be bound by income level and educational skills.

Therefore, although telephone penetration rate is relatively low, it disseminates rapidly in many developing countries, even faster than the high-income developed countries. On the other hand, the proportions of telephone and urbanization rate also show a negative correlation with diffusion rate. This also shows that urban market has been gradually saturated; telephone consumption may have shifted to lowincome rural groups. The empirical results are further proof of what we have seen in the analysis of the status quo: the increasing penetration level in developing countries. 
Table 1. the Regression Results of Telephone Diffusion Speed

LOG (PHONE04)-LOG (PHONE00)

\begin{tabular}{cccc}
\hline model & I & II & III \\
Sample & 43 & 43 & 43 \\
adjusted $R^{2}$ & 0.867686 & 0.869778 & 0.861478 \\
F-test value & $46.90435^{* * *}$ & $41.07527^{* * *}$ & $30.02225^{* * *}$ \\
\hline C & $2.559346^{* * *}$ & $1.973846^{*}$ & $2.565862^{* *}$ \\
& $(0.741878)$ & $(1.026154)$ & $(1.182722)$ \\
LOG(PHONE00) & $-0.195873^{* * *}$ & $-0.196935^{* * *}$ & $0.224093^{* * *}$ \\
& $(0.062549)$ & $(0.060726)$ & $(0.069968)$ \\
LOG(INCOME) & $-0.182133^{* *}$ & -0.123460 & -0.152468 \\
& $(0.079832)$ & $(0.081569)$ & $(0.096107)$ \\
LOG(EDU) & 0.243570 & 0.286688 & 0.218543 \\
& $(0.200328)$ & $(0.209274)$ & $(0.268839)$ \\
LOG(TRADE) & $0.093047^{* * *}$ & $0.090834^{* * *}$ & $0.082587 * *$ \\
& $(0.030106)$ & $(0.028245)$ & $(0.037379)$ \\
LOG(HTECH) & $0.046882^{* *}$ & $0.047906^{* * *}$ & $0.054580^{* *}$ \\
& $(0.019887)$ & $(0.020711)$ & $(0.024225)$ \\
LOG(CITY) & -0.180776 & -0.203195 & -0.173752 \\
& $(0.130678)$ & $(0.124585)$ & $(0.174452)$ \\
DD & & -0.102131 & \\
& & $(0.085679)$ & \\
D1 & & & -0.027402 \\
& & & $(0.077170)$ \\
D2 & & 0.052103 \\
& & & $(0.081022)$ \\
D3 & & 0.029792 \\
& & & $(0.121575)$ \\
\hline
\end{tabular}

${ }^{*},{ }^{* *}$ and $* * *$ indicate significance at $10 \%, 5 \%$ and $1 \%$ respectively, standard errors in parentheses; White heteroskedasticity-consistent standard error and covariance estimates.

It is very notable that a country's market openness and the pace of proliferation of technology influence the phone diffusion speed, the diffusion rate of telephones would rise when the level of globalization and technological develops in a country, it shows that the importance of current trade and technology to the demand for phones and other ICT products. Virtual region and state variables in the model is not significant, but since the variables impact the income per capita level, actually shows the income differences between developed and developing countries and regions.

When the ICT indicator is personal computers, the estimates yield an insignificant model. However, the statistical model is still significant (significantly higher than the $1 \%$ level), which shows the income per capita, educational level, quality of government regulation and the openness of the market are still relevant factors affecting the proliferation of personal computers.

When the ICT indicator is personal computers, the result shows the main impact of the proliferation of Internet users during $2000-2004$, the adjusted $R^{2}$ is 0.83 . 
Telephone mainlines per 1,000 inhabitants and Internet users are in the significant correlation (significantly higher than the $1 \%$ level), indicating that with the rapid development of the Internet, telephone dial-up access is still the main channel, infrastructure is an important factor affecting the rapid proliferation of the Internet.

Meanwhile, income per capita and level of education remain a negative correlation with Internet users, but it was not significant. I interpret the result from the following perspectives. Firstly, "Internet users" are inhabitants who take more than one hour a week online, it may overestimate the number of Internet users; secondly, most Internet users have no fixed source of income, including students. Although the number of Internet is growing faster, the use of the Internet is not clear verification purposes. This is further illustrated right that analysis the ICT only as a consumer goods, not a product.

However, the market openness, the level of urbanization and regulation quality index were positively correlated with the Internet diffusion speed, Although not very significant, but it also shows a certain degree of maturity on the Internet, For the Internet plays an important role in the proliferation of trade, trade can promote the proliferation of the Internet too. Meanwhile, the popularity of Internet was later than telephones, cities are mainly market of the Internet, popularization of the Internet plays an important positive impact and good government regulation of emerging Internet is more conducive to raise the speed.

From empirical results of the Internet hosts diffusion speed, we can see that the socio-economic variables and technology diffusion model can not reflect the determinants of Internet hosts diffusion. This explains the proliferation of Internet hosts differs from the general characteristics of telephones, Internet users and other infrastructure, but more emphasis on the production of capital goods as well as the use of economic value, hence it need further analysis in the future.

In short, in this paper, the Gompertz technology diffusion model is used to come with the empirical results which are very different from previous studies, possible reasons are as follows. Firstly, the basic indicators selected are not much different from previous studies, but the result was quite different. It shows that in the 20th century, especially in the late 1990 s, the proliferation of high-speed universal ICT development period, the developing country get access to a fast rate of proliferation, to be more open and its capability of science and technology promoting the development of the market, rather than income per capita and level of education, it proves that a certain degree of economic convergence; Secondly, the selected proxy variables may not accurately reflect the true situation of the variables that affect the empirical results; Thirdly, during the annual rate of the proliferation may be influenced by the random events of the period; Finally, A national ICT diffusion rate and the current level of popularity may be different factors.

\section{Conclusions}

International digital divide is a particularly significant phenomenon between the developed and developing countries. From the overall growth trend, diffusion rate of four ICT products rapidly rises particularly in 2000 . On the other hand, in 
developing countries, the diffusion rate is relatively faster than it in developed countries. However, there is still a great gap between the absolute level of penetration, according to the existing speed and trends; it's difficult for developing countries to catch up with developed countries in the near future.

Since 2000 , the proliferation of telephones, personal computers and Internet users is different from the early trend, income per capita, the level of education are not important factors affecting ICT diffusion, but market openness, high-tech and the impact of the information infrastructure seemed to be speedy. This provides guidance and recommendations for developing countries to catch up.

The results show that if all countries adopted various "policy leverage" to promote market liberalization, technological innovations, and substantial investment in information infrastructure, the impact of international digital divide will reduce. If the developing countries wish to catch up with developed countries, they should strengthen cooperation in international trade and enhance independent innovation in science and technology, encouraging deregulation in the telecommunications services through a variety of approaches for universal access, from the export of technology to speed up the transfer of technology.

As far as China is concerned, firstly, combined with the balanced development strategy of China's inter-regional, China should emphasize the applicability of ICT, focus on the application of ICT in backward areas, and avoid the path of "individual pursuit of high technology indicators" partial road. Secondly, with respect to technology import, a flexible approach should be developed to a variety of technical trade through licensing trade, cooperative production, technical services, consultancy, import key equipment and complete sets of equipment and other means, find an independent innovation and development way to combine domestic and international technology transfer.

\section{References}

1. M. Granovetter, "The Strength of Weak Ties: A Network Theory Revisited", Sociological Theory, San Francisco: Jossey-Bass, 1983.

2. G8, "Digital Opportunities for All: Meeting the Challenge, Report of the Digital Opportunities Task Force", including a proposal for a Genoa Plan of Action, 2001.

3. P. Norris, Digital Divide: Civic Engagement, Information Poverty, and the Internet Worldwide, Cambridge University Press , 2001.

4. C. Shapiro, H. Varian., Information Rules: A Strategic Guide to the Network Economy, Cambridge, MA: Harvard Business School Press, 1999.

5. E. Hargittai, "Weaving the Western Web-Explaining Differences in Internet Connectivity among OECD Countries" [J]. Telecommunications Policy, 1999: 701-718.

6. Shengya, Technology innovation diffusion and New Products Marketing, China

Development Publication, 2002.

7. S. Kiiski, and M. Pohjola. Cross-country Diffusion of the Internet, United Nations

University, World Institute for Development Economic Research, 2001. 